\title{
AÇÕES AMBIENTAIS COM PESSOAS QUE CONVIVEM COM DEPRESSÃO EM UM CENTRO DE ATENÇÃO PSICOSSOCIAL
}

\author{
Marcelo Nunes da Silva Fernandes ${ }^{1}$, Paulo Edelvar Corrêa Peres ${ }^{2}$ \\ ${ }^{1}$ Especialista em Educação Ambiental - UFSM \\ 2 Professor/orientador no Curso de Pós Graduação em Educação Ambiental da UFSM
}

\begin{abstract}
RESUMO
Pesquisa de caráter não-formal, desenvolvida junto à Oficina Terapêutica de Leitura do Centro de Atenção Psicossocial 1 (CAPS 1) de São Sepé/RS, objetivando buscar por meio de debates e dinâmicas de grupo a eleição de valores acerca do meio ambiente e uma conscientização da realidade do nosso planeta. Ao abordar a situação do meio ambiente, pode-se observar que através de atitudes simples como uso da água de forma consciente, cuidados com o lixo doméstico, separação e destino correto dos resíduos, entre outras, podem contribuir para o equilíbrio entre o homem e o ambiente, respeito e cuidado à vida nas diferentes formas.
\end{abstract}

PALAVRAS CHAVES: Educação Ambiental, saúde, vida.

\section{ABSTRACT}

The Research on a non-formal was developed by the therapeutic workshop reading of Psychosocial Care Center 1 (CAPS 1) Sao Sepe / RS, aiming to get through debates and group dynamics of the election of values about the environment and an awareness of the reality of our planet. In addressing the situation of the environment, we can see that through simple actions such as use of water in a conscious way, taking care of household waste separation and the correct destination of the waste, among others, can contribute to the balance between man and environment, respect and care for life in different ways.

KEY WORDS: environmental education, health, life.

\section{INTRODUÇÃO}

Vivemos numa sociedade, onde novas tecnologias surgem a cada dia e as informações estão presentes na vida da maioria das pessoas, porém, a falta de conhecimento ainda faz a sociedade ter uma visão das pessoas que convivem com depressão como se fossem "loucos", uma visão que precisa e deve ser mudada. A realidade é que a depressão pode ser tratada e controlada, promovendo um cotidiano saudável às pessoas que seguem o tratamento com aderência. 
ISSN:

A diferenciação entre as pessoas que convivem com depressão e as convencionais, pode ter implicações na vivência da enfermidade, a partir do diagnóstico de depressão. Os modos de enfrentamento diante de uma nova situação, como a de viver com uma doença crônica, modificam-se dependendo das características pessoais e sócio-ambientais. A equipe de saúde deve levar em consideração esses aspectos na elaboração do plano terapêutico. A oferta de atendimento psiquiátrico, psicológico, individual e a participação em oficinas terapêuticas devem ser disponibilizadas ao usuário.

A participação em oficinas terapêuticas em instituições de saúde torna-se importante para que a pessoa possa conhecer diversas formas de lidar com a condição de depressiva, a partir da troca de experiências com outros usuários.

Em 2007 foi criada a Oficina Terapêutica de Leitura no Centro de Atenção Psicossocial 1 (CAPS 1) de São Sepé/RS, com a intenção de proporcionar aos usuários do serviço um espaço de reflexão a cerca das nuances que a doença traz ao indivíduo. É um momento de reflexão acerca do tratamento, de situações vivenciadas como o preconceito e a não aceitação da doença, estímulo ao autocuidado e troca de experiências.

Algumas pessoas que convivem com depressão ocultam e não aceitam o diagnóstico, não se tratando, quando começam a ter alguma manifestação séria que as obrigue a procurar o serviço especializado, é que muitas vezes procuram ajuda. Outras após passar pela fase de negação resolvem procurar ajuda, orientação sobre a doença e cuidados para evitar recaídas.

As pessoas que convivem com depressão têm todo o apoio e tratamento tanto com relação à saúde física e psicológica gratuita em setores públicos brasileiros, mas muito ainda pode ser feito para melhorar a visão com relação ao preconceito e a melhora na qualidade de vida dessas pessoas. Esse preconceito, a maioria das vezes ocorre por medo e falta de informação.

O que difere não é a visão que se tem da doença, mais a visão preconceituosa de uma sociedade que ao invés de ver pessoas, visualiza posturas e costumes.

A depressão tem peculiaridades e particularidades que a diferencia do atendimento a outros pacientes com doenças igualmente graves, pois lidar com as pessoas que convivem com depressão nos reporta a questões que envolvem a doença e a própria perspectiva existencial. Tem uma ampla repercussão atingindo além da pessoa, todo o seu contexto sócio-familiar deixando de ser um problema só médico como também social, econômico, psicológico, político justificando-se a necessidade de uma equipe interdisciplinar no atendimento a essa clientela.

Aliado a isso, a Educação Ambiental pode proporcionar uma maior interação do ser humano em questão, de forma a promover ações de valorização da vida, possibilitando aos envolvidos, oportunidades para desenvolver uma sensibilização aos problemas ambientais e uma reflexão a respeito desses problemas e a busca de soluções. Essas ações de sensibilização devem ser um caminho para tornar as pessoas conscientes do quanto são importantes as suas atitudes, pois sensibilizar é "cativar" os participantes para que suas mentes se tornem receptivas às informações a serem transmitidas.

Nesse contexto, o objetivo geral da pesquisa foi aproximar e levar esclarecimentos possibilitados pela Educação Ambiental de forma a melhorar a vida e a convivência dos participantes da Oficina Terapêutica de Leitura do CAPS 1 de São Sepé/RS, à influência dos fatores ambientais na vida de qualquer indivíduo. E, como objetivos específicos, procurou-se eleger valores para cada indivíduo acerca do meio ambiente, considerando-o como parte integrante do mesmo, além da conscientização acerca da realidade do nosso planeta e de suas mudanças cotidianas, buscando interferir de forma positiva na sua realidade, por meio da reflexão sobre 
valores relacionados aos temas ambientais e a contextualização da educação ambiental na promoção de saúde.

Portanto, a pesquisa justifica-se pela necessidade cada vez maior das pessoas desenvolverem uma consciência ecológica, bem como pela preocupação com as causas ambientais, buscando um mundo mais sustentável, oportunizando desenvolver uma sensibilização aos problemas ambientais e uma reflexão a respeito desses problemas e a busca de soluções. Somam-se a isso, a possibilidade de esclarecer dúvidas sobre temáticas ambientais, esclarecer assuntos discutidos na realidade e intervir, nos diferentes aspectos, com ações ambientais, para que o indivíduo possa realizar mudanças significativas no meio onde vive. Assim, a pesquisa está estruturada em quatro capítulos. O primeiro consta do referencial teórico, o segundo, apresenta a metodologia e o desenvolvimento da pesquisa, o terceiro traz a análise e discussão das atividades desenvolvidas e, no quarto capítulo as conclusões.

\section{Contextualização das pessoas que convivem com depressão no âmbito da Educação Ambiental}

Ao descobrir serem portadoras de depressão as pessoas reagem de diferentes formas. Algumas ocultam e não aceitam o diagnóstico, não se tratando, até ter alguma manifestação séria que as obrigue a procurar o auxílio médico, outras após passar por essa fase resolvem assumir-se como portadoras, fazendo tratamento, cuidando e valorizando sua saúde e vida, acima de qualquer coisa, buscando sempre o seu bem-estar e qualidade de vida.

A pessoa portadora de depressão também pode ficar sujeita a desenvolver sintomas como tristeza profunda, falta de apetite, alterações do sono, entre outros, sendo estes os principais fatores relacionados à maior incidência de suicídio, o qual é a principal causa de mortalidade relacionada à depressão.

Segundo Morin (2000) devemos assumir as conseqüências da situação marginal, periférica que é a nossa. Como seres vivos deste planeta, devemos reconhecer nossa identidade terrena física e biológica. Após o sentimento de "pertencimento" o ser humano passa-se a reconhecer-se como parte do meio ao qual deve desenvolver valores de preservação.

Nesse sentido, os saberes e aprendizados ambientais contribuem para melhoras na vida e no cotidiano das pessoas que convivem com depressão e também para o desenvolvimento de um pensar que é nas pequenas ações que começa a construção por um mundo melhor, onde possa existir mais harmonia homem-natureza.

Estabelecendo um ambiente de observação e escuta, compartilhando estes momentos vivenciados pela realidade na busca de soluções para os desafios em que são deparados, verificam-se a importância de cada vez mais ações de conscientização, visando mudar a realidade dos problemas ambientais e conseqüentemente com efeitos positivos para a saúde.

Segundo Morin (2000) devemos desenvolver a consciência ecológica, isto é, a consciência de habitar, com todos os seres mortais, a mesma esfera viva, nutrindo a aspiração de convivibilidade sobre a Terra.

Transformar-se em um sujeito ecologicamente correto é um processo longo e que exigiria mudanças no modo de agir e viver ao qual se está acostumado, porém se cada vez mais ações na busca de conscientização e busca por um modo de vida mais sustentável forem tomadas, estaremos no caminho certo por um mundo mais saudável. 
ISSN:

De acordo com Guattari (1990), só a "ecososofia", uma articulação entre o que considerou "os três registros ecológicos", meio ambiente físico, relações sociais e subjetividade humana, é que pode dar conta das questões ambientais.

Nesse contexto, as pessoas que convivem com depressão podem mudar sua visão de homem como parte isolada, e compreender sua importância como parte do ambiente, percebendo as implicações de suas ações na saúde e no meio ambiente agora e para as futuras gerações.

Assim, é necessário o entendimento por parte da população a importância do sentir-se e assumir-se como parte do ambiente e preservá-lo.

Segundo o CONAMA - Conselho Nacional do Meio Ambiente - a Educação Ambiental é definida como um processo de formação e informação orientada para o desenvolvimento da consciência critica sobre as questões ambientais, e de atividades que levem à participação das comunidades na preservação do equilíbrio ambiental.

A Lei Federal no. 9.795 de 27 de abril de 1999 estabeleceu como conceito da educação ambiental não-formal as ações e práticas educativas voltadas à sensibilização da coletividade sobre as questões ambientais e à sua organização e participação na defesa da qualidade do meio ambiente, devendo o Poder Público, em níveis federal, estadual e municipal, incentivar a ampla participação da escola, das universidades e de organizações não-governamentais na formulação e execução de programas e atividades vinculadas à educação ambiental não-formal.

No Plano Nacional, desde 1981, a Lei no. 6.938, que dispõe sobre os fins, mecanismos de formulação e aplicação da Política Nacional do Meio Ambiente, consagra a Educação Ambiental e estabelece no seu décimo princípio: "Educação Ambiental a todos os níveis do ensino, inclusive a educação da comunidade, objetivando capacitá-la para participação ativa na defesa do meio ambiente".

Segundo a Agenda 21 o desafio político da sustentabilidade, apoiado no potencial transformador das relações sociais encontra-se estreitamente vinculado ao processo de fortalecimento da democracia e da construção da cidadania. A sustentabilidade traz uma visão de desenvolvimento que busca superar o reducionismo e estimula um pensar e fazer sobre o meio ambiente diretamente vinculado ao diálogo entre saberes, à participação, aos valores éticos como valores fundamentais para fortalecer a complexa interação entre sociedade e natureza.

Nesse sentido, é essencial que a Educação Ambiental impulsione ações conscientizadoras e sensibilizadoras que assumam um compromisso com a formação de valores de sustentabilidade, como parte de um processo coletivo.

Destaca-se o papel das Instituições de Saúde neste tipo de ação, uma vez que possuem maior conhecimento da comunidade para qual disponibilizam os seus serviços, no caso do CAPS 1 de São Sepé/RS, as ações com Educação não-formal viriam a colaborar com a comunidade na vida presente e futura.

$\mathrm{Na}$ área da saúde, as abordagens mais globais do ponto de vista ecológico são muito recentes, datando do final da década de 70, quando tanto ambientalistas quanto sanitaristas, tanto investigadores quanto gestores começaram a perceber a necessidade de integrar mais suas ações e suas abordagens em favor da qualidade de vida das populações concretas.

Portanto, se queremos compreender o impacto da atividade humana sobre o ambiente e sobre a saúde, é necessário criar estratégias específicas que, a partir de conhecimentos disciplinares e práticas setoriais, caminhem para uma abordagem transdisciplinar (MINAYO \& MIRANDA, 2002, p.175). 
ISSN:

Utilizar dessa força de vontade e empenho que se percebeu em muitos para enfatizar a questão ambiental e até mesmo mostrar que essas pessoas apesar de todos esses problemas enfrentados depois do diagnóstico, lutam por um mundo melhor para si e para seus semelhantes.

O saber ambiental levanta a questão da diversidade cultural no conhecimento da realidade, mas também o problema da apropriação de conhecimentos e saberes dentro de diferentes ordens culturais e identidades étnicas. O saber ambiental não só geram um conhecimento científico mais objetivo e abrangente, mas também produzem novas significações sociais, novas formas de subjetividade e de posicionamento diante do mundo (LEFF, 2001, p. 231).

Visando bem mais que a apropriação e sim que esses saberes e aprendizados pudessem contribuir para melhoras na vida e no cotidiano das pessoas que convivem com depressão que participam da Oficina Terapêutica de Leitura, é nas pequenas ações que começa a caminhada por um mundo melhor, onde possa existir mais harmonia homem-natureza. O processo de tornar-se um ser humano ecologicamente correto é longo, e para que isso ocorra precisaria que muitos comportamentos fossem readaptados, a começar pela sensibilização da relevância em mudar tais comportamentos.

Nesse sentido, propor questões, desafiar e problematizar a partir do que o sujeito já dispõe enquanto conhecimento construído traz novas perspectivas e cria condições necessárias para a produção de novas respostas mais eficazes diante do problema inicial.

\section{Educação em saúde}

A educação está fundamentada em princípios filosóficos e estruturada de acordo com o momento histórico vivido pela sociedade. Tem, portanto, um papel importante na humanização das pessoas e na sua transformação individual e social.

Enquanto processo histórico, a educação evolui na medida em que a sociedade evolui, é um processo dinâmico e flexível que possibilita ao ser humano, o desenvolvimento de suas potencialidades, podendo atingir autonomia e decidir sobre seus objetivos e ações.

A educação em saúde se insere neste contexto promovendo o autocuidado e capacitando o homem para a reflexão, autonomia e criticidade. Na "visão" de Vasconcelos (1991) a educação em saúde é um processo evolutivo baseado em um diálogo onde ocorre interação entre o saber científico e o popular, de forma que a atitude de saber ouvir e respeitar o conhecimento do outro é imprescindível para se realizar uma educação em saúde eficaz.

Dessa maneira, o processo de educação em saúde possibilita que haja uma compreensão entre profissional e indivíduo, permitindo a este, por meio do processo ensino-aprendizagem, encontrar as soluções mais adequadas para melhorar sua qualidade de vida.

Neste contexto é que os profissionais da área da saúde devem reafirmar os seus compromissos com o ser humano. Os profissionais de saúde, como mediadores das trocas de experiências e informações, com a população por eles assistida, devem estar preparados para exercer seu papel de educadores capazes de assumir a educação em serviço, planejar e implementar ações de educação em saúde direcionada à população.

Percebe-se, portanto, que a educação é um processo construtivo que necessita da participação da comunidade e do comprometimento dos profissionais de saúde, bem como da ciência desses de que cada indivíduo está inserido em um contexto sócio-econômico-cultural e educacional diferente. 
ISSN:

Assim, nesta nova caminhada, destaco que, os profissionais de saúde vêm procurando utilizar a educação em saúde como processo na promoção de saúde e conseqüentemente, bemestar da população a quem disponibilizam seus serviços. É nessa perspectiva que o cuidar educando pode ser exercido pelos profissionais de saúde. Por meio da educação, educam enquanto aprendem e aprendem para educar, havendo troca e crescimento mútuo, a partir da realidade vivenciada. Para isso, é importante que haja respeito, compreensão, responsabilidade e principalmente afeto entre os participantes do processo educativo.

Os profissionais de saúde também devem enfatizar como meta da educação em saúde, orientar/ensinar as pessoas a viverem da maneira mais saudável possível.

Assim, destaco a importância da educação em saúde, delineada na forma de ações educativas estimulando o diálogo e a participação, a fim de promover o conhecimento à clientela assistida.

Aliado a isso, entendo que, a educação em saúde é também um processo educativo social. Para Freire $(1980 ; 1987 ; 1992 ; 1996)$ a educação é um processo pelo qual as pessoas vão se completando durante toda a vida na busca do "ser mais" com o "outro", ou seja, ao se educar, a pessoa tem consciência do seu desenvolvimento enquanto ser inacabado, e busca o ser mais com a existência das outras pessoas.

Assim, o sentido da educação em saúde decorre do fato das pessoas serem incompletas e estarem em relação com outras pessoas, em um ato político, no sentido de "ser mais com o outro", sendo esta a busca dos seres humanos ao se educarem. Em outras palavras, a educação em saúde tem um amplo caráter que transcende um espaço de formação, mostrando que as ações junto aos métodos, caracterizam-se como uma reelaboaração da realidade.

\section{METODOLOGIA}

O CAPS 1, localizado em São Sepé/RS, é coordenado pela Secretaria Municipal de Saúde. O atendimento ocorre de segunda à sexta-feira, no horário das 8 às 18 horas. Neste período, são oferecidos os seguintes serviços: consultas médicas psiquiátricas e de clínica geral, acolhimentos, atendimento psicológico, consultas de enfermagem, visitas domiciliares e oficinas terapêuticas.

Para seu efetivo funcionamento, o Centro dispõe de duas médicas psiquiátricas, um médico clínico geral, um enfermeiro, uma assistente social, quatro psicólogos, uma técnica de enfermagem, uma recepcionista, duas auxiliares de serviços gerais, quatro monitores, uma acadêmica de psicologia e três voluntárias.

As pessoas que convivem com depressão são acompanhadas mediante consultas psiquiátricas, de clínica geral, de enfermagem, visitas domiciliárias e oficinas terapêuticas, como por exemplo, a Oficina Terapêutica de Leitura onde este trabalho foi realizado.

A Oficina Terapêutica de Leitura se forma com a participação das pessoas que convivem com depressão usuárias do serviço, que procuram a oficina como apoio a nova situação que estão enfrentando. Os encontros da oficina de leitura têm participação do enfermeiro que tem a função de facilitador e coordenador, profissionais do CAPS 1 e de outros profissionais dos serviços de saúde do município de São Sepé/RS que são convidados a participar da oficina conforme a necessidade e desejo dos participantes. 
ISSN:

É um espaço de discussão e aconselhamento aos usuários do serviço, que tem finalidades diversas que começam pela adesão ao tratamento, aceitação da doença a assuntos diversos, visando melhoria na qualidade de vida das pessoas que convivem com depressão.

Possui encontros semanais nas segundas-feiras, com uma hora de duração, com atividades diversificadas como leituras de textos, dinâmicas de grupos, debates, visitas à biblioteca do município, entre outras, atividades que proporcionam a troca de experiências e o diálogo entre os integrantes.

Nos encontros são discutidos assuntos diversos visando uma melhor aceitação e melhorias na adesão ao tratamento medicamentoso e psicológico com a troca de experiências entre os participantes buscando sanar dúvidas e buscar melhorias na qualidade de vida aos usuários.

Os critérios de seleção para participar da oficina são o diagnóstico de depressão e o interesse por parte das pessoas, até mesmo para conviver e trocar experiências com pessoas que possuem e enfrentam problemas semelhantes.

\section{RESULTADOS E DISCUSSÃO}

Os sujeitos da pesquisa foram 5 pessoas que convivem com depressão, ou seja, os 5 integrantes da oficina, sendo quatro mulheres e um homem, com faixa etária entre 40 e 60 anos. Este número constitui o seu limite máximo, o qual foi estipulado em reunião de equipe em decorrência das atividades de leitura exigem concentração e um grupo muito grande poderia prejudicar o andamento da mesma.

O desenvolvimento da pesquisa foi estruturado em dois momentos distintos. No primeiro momento, o trabalho iniciou-se com discussões e conhecimento da realidade de cada um, vendo suas dificuldades e problemas enfrentados dentro da sua comunidade relacionada às questões ambientais.

Posteriormente, busquei ações que visaram melhor compreensão a tais questões buscando esclarecê-los em virtude de suas condições, para desmistificar preconceitos e melhorar a qualidade de vida dessas pessoas em seu dia a dia e consigo mesmo.

Teve momentos de abertura desse espaço para que os familiares e acompanhantes dos participantes, buscando nessas conversas a importância da presença de tais, para uma melhor aderência ao tratamento e melhoras do paciente evitando a depressão em muitos casos e a exclusão social. Promovendo uma melhor consciência critica e fazendo com essas pessoas sintamse capazes de se empenhar em uma causa para ajudar seus semelhantes e até mesmo diminuir essa visão de preconceito que muitos ainda têm sobre pessoas portadoras de depressão.

As práticas de Educação Ambiental na Oficina Terapêutica de Leitura deram aos integrantes uma oportunidade de reflexão, abrindo aos sujeitos novas possibilidades de problemática ambientais e novas compreensões das relações sujeito-mundo, construindo sensibilizações, posturas éticas e valores. Para que ao sair dos encontros eles passem esses valores à diante ou ajam criticamente frente a situações de degradação ambiental, até mesmo denunciando a órgãos competentes.

Utilizando de termos como o "cuidar" nas diferentes formas, falava-se da questão da importância do cuidado com o Planeta, até o cuidado com si próprio com comportamentos de "preservação e conservação" da saúde de cada um. 
Os encontros ocorreram no segundo semestre de 2009, entre os meses de julho e agosto, baseados em temas diversos, partindo do interesse dos integrantes da Oficina Terapêutica de Leitura, ou seja, das pessoas que convivem com depressão.

No primeiro encontro, realizamos uma conversa inicial sobre os objetivos do projeto, levantamento de interesses, no que consistiria e como seriam feitos os próximos encontros.

Nesse primeiro contato, através dos debates e da participação dos integrantes da oficina, percebeu-se o interesse deles pela temática, ao relatarem os problemas cotidianos que enfrentam em suas comunidades com relação ao lixo, poluição do ar, desperdício da água, entre outros. Destaco que nesse encontro estavam presentes os 5 integrantes da oficina.

Ainda, nesse primeiro encontro foi proposto aos integrantes que buscassem no seu cotidiano soluções para o enfrentamento de tais problemas, mediante o seguinte questionamento: quais mudanças poderiam ser tomadas para possibilitar melhorarias dos problemas que foram discutidos nesse encontro?

No segundo encontro havia os mesmos 5 integrantes. Retomamos o que havia sido discutido no encontro anterior e à pergunta do primeiro encontro com respostas significativas que foram desde o fato de começarem a separar o lixo em casa, conscientização sobre desperdício de água, no banho demorado, ao escovar os dentes com a torneira aberta e redução no número de lavagens de roupa na máquina de lavar. Dessa forma, percebi que a conscientização pode ser feita em simples atos de conversas e no pensar por parte da população.

O terceiro encontro contou com a participação dos 5 integrantes, onde se discutiu em cima da "Carta da Terra", na qual o nosso Planeta pede socorro aos seus inquilinos, para que medidas e mudanças sejam tomadas para que a vida dos seres vivos não seja extinta. A missão da Carta da Terra é promover a transição para formas sustentáveis de vida e de uma sociedade global fundamentada em um modelo de ética compartilhada, que inclui o respeito e o cuidado pela comunidade da vida, a integridade ecológica, a democracia e uma cultura de paz.

Foi debatido o conteúdo da Carta e fornecido cópias para os integrantes da oficina.

No encontro seguinte, havia 4 integrantes, pois uma participante do sexo feminino não pode comparecer por motivos familiares. Foi trabalhado o cuidado de si próprio, alimentação adequada, uso correto da medicação, sono e repouso. Continuando o questionamento proposto no primeiro encontro, um dos integrantes entre outros depoimentos, relatou que conseguiu diminuir a quantidade do consumo de água em suas atividades diárias, como por exemplo, não escovar os dentes com a torneira aberta, mostrando estar consciente do desperdício de um bem natural esgotável.

No quinto encontro, discutimos a questão do lixo, separação e cuidados. Discutiu-se sobre como é realizada a coleta de lixo no município, a qual acontece da mesma forma na área central e nas comunidades da cidade.

O caminhão de recolhimento conta com o motorista e dois funcionários responsáveis pela coleta propriamente dita. Os moradores estocam o lixo dentro de casa e ficam aguardando o dia e horário da coleta.

$\mathrm{Na}$ reunião posterior havia 4 integrantes, pois o participante do sexo masculino não compareceu devido a uma viagem. Trabalhamos no sentido de ir além dos problemas ambientais e acentuar os problemas sociais, buscando refletir sobre o que deixaremos as futuras gerações. Isto suscitou bastantes questionamentos entre os participantes, como por exemplo, como o Planeta poderia ser diferente e melhor, se cada um fizesse a sua parte.

No encontro final, estavam presentes os 5 integrantes. Realizamos uma visita ao Centro Cultural do município de São Sepé/RS, onde realizamos uma confraternização e mensagem final, 
ISSN:

momento esse, onde se pode perceber a satisfação de muitos integrantes que participaram desse momento ao realizar uma avaliação do projeto por parte dos integrantes de forma falada, onde cada um pode colocar-se, ficando evidente para muitos a importância de preservação do ambiente e que foram criados para si valores individuais referentes ao nosso planeta.

Durante o trajeto do CAPS 1 até o referido Centro, observou-se lixos jogados, no qual os integrantes fizeram críticas as pessoas que os jogaram ali, mesmo tendo lixeiras nas proximidades, evidenciando que se deve cada vez mais trabalhar a população em geral no sentido de reeducação ambiental.

Participar e executar este trabalho foram de grande relevância, uma vez que trabalhar questões ambientais com pessoas que convivem com depressão motivou-me a persistir e concretizar os objetivos inicialmente propostos.

Ver sorrisos no rosto de quem enfrenta problemas de preconceito e aceitação, até mesmo de si próprio e da sua situação, dá maior sentido e estímulo para que mais seja feito, isso era o que sentia a cada dia, depois de terminar a ação na Oficina Terapêutica de Leitura.

Perceber o interesse, em tentar mudar atitudes cotidianas, buscando melhorias na realidade, dentro do meio em que vivem, esse era o tema mais discutido e relembrado ao longo dos encontros, pois se sabe que o processo para tornar-se um sujeito ecologicamente correto é longo e contínuo, e que para que se atinja o objetivo é preciso que haja sensibilização, ou seja, que se perceba e eleja para si valores de comprometimento da importância que tal mudança trará de positivo para a vida de cada individuo e suas gerações futuras.

Começando a mudar a partir das pequenas ações como economizar água nos momentos de higiene pessoal, administrar corretamente energia da sua residência, dar o destino adequado ao lixo, optar por produtos ambientalmente corretos, dentre muitas atitudes que temos o conhecimento de ser a correta.

O simples fato de alguém querer realizar uma ação de promoção da saúde na oficina gera aceitação pela grande maioria, a partir do momento que eles sintam confiança. Alguns reclamam que muitas pesquisas são realizadas, porém muitas vezes, o resultado não chega até eles, ou não fica totalmente esclarecido. Mas o que mais ficou claro é que a maioria dos participantes tem empenho e força de vontade para mudar muitos aspectos na sociedade, porém há carência de ações e espaços, nos quais eles possam trocar idéias, falar, ouvir e serem ouvidos, enfim, sentirem-se atuantes e não apenas sujeitos de pesquisa, participar de qualquer ação em que eles possam trocar experiências com pessoas que passam pelos mesmos problemas, enfrentam as mesmas dificuldades, tentando mudar a forma de perceber a situação, com novos olhares em prol da vida.

Com relação às avaliações das atividades desenvolvidas na oficina terapêutica de leitura, todos pontuaram de forma positiva o trabalho na conscientização ambiental, citando fatos nos quais tentaram conscientizar vizinhos, familiares, com os materiais fornecidos nas oficinas, evidenciando que devido às participações no grupo, tornaram-se até mesmo agentes conscientizadores na sua comunidade, expandindo-se assim o objetivo de eleição de valores individuais. 
ISSN:

\section{CONCLUSÕES}

Levar as questões ambientais a pessoas que convivem com depressão foi uma tarefa difícil e ao mesmo tempo estimuladora. Percebeu-se que durante o desenvolvimento do trabalho, o interesse, a participação e a preocupação de levar até os membros de suas famílias e às pessoas com quem convivem, sugestões e mudanças de atitudes que efetivamente contribuem para o processo de melhoria ambiental.

Conseguir que essas pessoas participem desse processo modificando suas rotinas, praticando e repassando valiosas informações, como a diminuição do consumo de água na lavagem de roupas, lavagem das mãos, preparo dos alimentos e separação do lixo, contribuiu para expandir a eleição de valores individuais, por meio da conscientização nas comunidades em que residem, através de conversas com vizinhos e familiares.

É difícil trabalhar em uma oficina diversos aspectos de forma a ficar atrativo a todos, mas isso foi encarado como um desafio diário na busca da sensibilização, com materiais acessíveis e de fácil compreensão a todos de forma a atingir a confiança dos membros.

Acredito ter alcançado o objetivo de sensibilização que é o processo inicial na busca da transformação do ser humano em sujeito ecológico, pois só cuidaremos quando nos sentirmos pertencentes e proprietários, sabendo da importância que o ambiente tem para a nossa sobrevivência e das gerações futuras.

Concluí-se que, com ações simples, foram atingidos os objetivos propostos, e que mesmo em uma oficina com as mais diversas preocupações, pessoas podem ser conscientizadas, mudando atitudes e contribuindo para a construção de um mundo mais sustentável, onde muito ainda pode e deve ser feito.

\section{REFERÊNCIAS}

FREIRE, P. Pedagogia da autonomia: saberes necessários a prática educativa. Rio de Janeiro: Paz e Terra, 1996.

Pedagogia da esperança: um reencontro com a pedagogia do oprimido. 6.

ed. Rio de Janeiro: Paz e Terra, 1992.

Pedagogia do oprimido. 17. ed. Rio de Janeiro: Paz e Terra, 1987.

. Conscientização: teoria e prática da libertação - uma introdução ao pensamento de Paulo Freire. 3 ed. São Paulo: Moraes, 1980.

GUATTARI, F. As Três Ecologias. Campinas: Papirus Editora, 1990.

LEEF, H. Saber ambiental sustentabilidade, racional idade, complexidade, poder. Petrópolis, RJ, Vozes, 2001.

MINAYO, M.C.S; MIRANDA, A. C. Saúde e ambiente sustentável: Estreitando nós. Rio de Janeiro: FIOCRUZ, 2002.

MORIN, E. Os sete saberes necessários à educação do futuro. São Paulo: Cortez, 2000.

VASCONCELOS, E. M. Educação popular nos serviços de saúde. 2 ed., São Paulo: Hucitec, 1991. 